\title{
1 Mass balance for POPs in hazardous and municipal solid waste
}

2

3 J. Van Caneghem ${ }^{\mathrm{a}^{*}}$, C. Block ${ }^{\mathrm{a}, \mathrm{b}}$, A. Van Brecht ${ }^{\mathrm{c}}$, G. Wauters ${ }^{\mathrm{c}}$ and C. Vandecasteele ${ }^{\mathrm{a}}$

4

$5{ }^{a}$ Department of Chemical Engineering, University of Leuven, De Croylaan 46, 3001

6 Heverlee, Belgium

$7 \quad$ b Leuven Engineering College Groep T, Department of Chemical

8 Engineering,Vesaliusstraat 13, 3000 Leuven, Belgium

$9 \quad{ }^{\mathrm{c}}$ Indaver NV, Dijle 17a, 2800 Mechelen, Belgium

\section{Abstract}

12 The amount of different persistent organic pollutants (POPs) in the input of waste

13 incinerators was compared to that in the output. Three cases were considered: a

14 rotary kiln incinerating hazardous waste, a grate furnace incinerating municipal solid

15 waste (MSW) and the same grate furnace co-incinerating plastics of waste of

16 electrical and electronic equipment (WEEE) and automotive shredder residue (ASR)

17 with MSW. The mass balance for PCBs in the rotary kiln indicates that these POPs

18 are destroyed effectively during incineration. The grate furnace can be a sink or

19 source of PCDD/Fs and PCBs depending on the concentrations in the incinerated

20 waste. In order to compare the total amount of POPs in input and output, a

21 methodology was developed whereby the amount of POPs was weighed according to

\footnotetext{
* Corresponding author. Tel.: +32 16 322353; fax +32 16 322991. E-mail address:
} jo.vancaneghem@cit.kuleuven.be 
22 minimal risk doses (MRDs) or cancer potency factors. For both incinerators the

$23 \mathrm{PCDD} / \mathrm{Fs}, \mathrm{PCBs}$ and polyaromatic hydrocarbons (PAHs) are the main contributors to

24 total weighed POP output. In MSW, the PCDD/Fs, PBDD/Fs and polybrominated

25 diphenylethers (PBDEs) are the main contributors to the weighed POP input. The

26 ratios of the weighed POP-input over -output clearly indicate that the rotary kiln

27 incinerating hazardous waste is a weighed POP sink. The grate furnace incinerating

28 MSW is a weighed POP sink or source depending on the POP concentrations in the

29 waste, but the difference between output and input is rather limited. When e.g. ASR

30 and plastics of WEEE, containing high concentrations of PBDEs and PCBs, are co-

31 incinerated in the grate furnace, it is clearly a weighed POP sink.

\section{Keywords}

34 Incineration; PCDD/F; PCB; Mass balance; Waste incinerator

\section{Introduction}

37 Waste incinerators are usually considered as sources of polychlorinated dibenzo-p-

38 dioxins and -furans (PCDD/Fs) as well as polychlorinated biphenyls (PCBs). Indeed,

39 these persistent organic pollutants (POPs) are unintentionally formed in the

40 incinerator and found in the output (Sakai et al., 1999; Abad et al., 2000; Sakai et al.,

41 2001; Abad et al., 2002). The waste to be incinerated, however, also contains a range

42 of POPs (Wilken et al., 1992; Mark et al., 1998; Sakai et al., 1998; Sakai et al., 1999;

43 Aae Redin et al., 2001; Sakai et al., 2001; Vehlow et al., 2002; Tange and 
44 Drohmann, 2005; Ishikawa et al., 2007; Morf et al., 2007; Schlummer et al., 2007). It

45 is generally assumed that the incoming POPs are destroyed during incineration and

46 that during the cooling of the flue gases new PCDD/Fs and PCBs are formed through

47 precursors or through de novo synthesis (Everaert and Baeyens, 2002; McKay,

48 2002). This assumption is supported by the analysis of the isomer and congener

49 distributions or so called "chemical fingerprints" of PCDD/Fs and PCBs; chemical

50 fingerprints of $\mathrm{PCDD} / \mathrm{Fs}$ and $\mathrm{PCBs}$ in waste are characterized by a significantly

51 different isomer and congener distribution than PCDD/F- and PCB-fingerprints in

52 flue gases and ashes of waste incinerators (Sakai et al., 1999; Abad et al., 2000;

53 Sakai et al., 2001; Abad et al., 2002).

54 Waste may contain a variety of toxic substances. Besides the POPs considered by the

55 Stockholm convention (PCDD/Fs, PCBs and polychlorinated pesticides including

56 hexachlorobenzene (HCB)), this paper also considers polybrominated dibenzo-p-

57 dioxins and -furans (PBDD/Fs), polybrominated diphenyl ethers (PBDEs),

58 polyaromatic hydrocarbons (PAHs) and di(2-ethylhexyl)phthalate (DEHP) in

59 different types of waste. All the above-mentioned toxic substances will for the sake

60 of brevity further be referred to as POPs.

61 Some studies compared the amount of PCDD/Fs in the in- and output of municipal

62 solid waste (MSW) incinerators (Abad et al., 2000; Abad et al., 2002; Giugliano et

63 al, 2002; Grosso et al. 2007) and concluded that MSW incinerators can act as

$64 \mathrm{PCDD} / \mathrm{F}$ sinks, depending on the assumed PCDD/F concentrations in the waste, on

65 the operating conditions and on the flue gas cleaning techniques. 
66 This study considers, in addition to PCDD/F, the amount of dioxin-like PCBs, PCBs,

67 PAHs and HCB in the outputs (flue gas, solid residues) of three different

68 installations:

69 - a BAT compliant rotary kiln incinerating hazardous waste

70 - a BAT compliant grate furnace incinerating MSW

71 - the same grate furnace co-incinerating automotive shredder residue (ASR)

72 and plastics of waste of electrical and electronic equipment (WEEE) with

73 MSW.

74 The purpose of the present paper is to answer the question whether the considered

75 waste incinerators are sinks or sources for the above mentioned groups of POPs.

76 In an attempt to estimate and compare the overall input and output of POPs - not just

77 the different POP-groups separately- a POP-weighing methodology is proposed and

78 applied to the three installations.

79 2. Materials and methods

$80 \quad 2.1$ Installations

81 The POPs in the in- and output are first compared for a rotary kiln, incinerating ca.

8290.000 tons/year of hazardous industrial waste at temperatures between 1000 and

$831200^{\circ} \mathrm{C}$. The flue gases are de-dusted with an electrofilter and then washed in a wet

84 gas washing unit. A fixed bed brown coal filter is used to remove PCDD/F. The

85 bottom ashes and the filtercake resulting from the wet gas washing are landfilled on a

86 class 1 landfill for hazardous inorganic waste. The boiler- and fly ashes first undergo

87 stabilization/solidification before landfilling. 
88 The POPs in the in- and output are also compared for a grate furnace (Vandecasteele

89 et al., 2007), incinerating ca. 400,000 tons/year of MSW and comparable industrial

90 waste at temperatures of at least $850{ }^{\circ} \mathrm{C}$. The flue gases resulting from the

91 incineration are led trough a steam boiler for heat recovery and are then cleaned in a

92 half wet gas washing unit. After injection of activated carbon to adsorb PCDD/F and

93 heavy metals, the gases flow through a baghouse filter and - before release to the

94 atmosphere - are further cleaned in a wet gas washing system consisting of a

95 quenching unit, an acid washing unit and an alkaline washing unit. The bottom ashes

96 are treated in a special wet treatment installation (Vandecasteele et al., 2007). After

97 addition of water, they are sieved and all parts larger than $50 \mathrm{~mm}$ are, after separation

98 of ferrous and non-ferrous metals, sent back to the incinerator. A screening and

99 washing installation further separates the particles smaller than $50 \mathrm{~mm}$ in 2 granulate

100 fractions $(2-6 \mathrm{~mm}$ and $6-50 \mathrm{~mm})$ and a sand fraction $(<2 \mathrm{~mm})$. Ferrous and non-

101 ferrous metals are separated from the granulate fractions, which can e.g. be used in

102 construction applications. The sand fraction is applied as construction material on

103 landfills. The boiler ashes and the flue gas cleaning residues are treated by

104 stabilization/solidification before they are landfilled on a class 1 landfill for

105 hazardous inorganic waste. All ferrous and non-ferrous fractions are recycled.

$106 \quad 2.2$ Sampling and analysis

$107 \quad$ 2.2.1 POP concentrations in the input waste

108 In the case of the rotary kiln, the considered POP input consists of 1,235 tons/year of 109 commercial 100\% PCB mixtures and 100 tons/year of $100 \%$ chlorinated POP 
110 pesticides. Their exact composition is not known. The POPs in the other hazardous

111 waste fractions are not considered; their contribution is estimated negligible

112 compared to the contribution of the PCBs and the chlorinated POP pesticides.

113 In MSW incineration the assessment of PCDD/Fs mass balances is complicated

114 because of lack of data on PCDD/Fs concentrations in the waste (Hedman et al.

115 2007). This conclusion holds for all the POPs considered in this paper. An extensive

116 literature search revealed substantial differences in the reported POP concentrations.

117 Therefore it was decided to work with concentration ranges as detailed in the

118 comment column of table 1. For PAHs, dioxin-like PCBs and HCB no representative

119 concentration data were found. All the bromine in the plastics of WEEE is supposed

120 to come from the PBDEs.

\section{$121 \quad$ 2.2.2 POP concentrations in the output}

122 The POP-concentrations in the outputs (flue gas, solid residues, waste water

123 treatment sludge) were determined on samples taken on site of the hazardous and

124 municipal solid waste incinerator plant.

125 The flue gas was monitored with equipment located on a measuring platform at the

126 stack of the respective installations. For PCDD/Fs, PCBs and PAHs, the flue gases

127 were sampled using sampling equipment of the AMESA (Adsorption Method for

128 Sampling) type, according to the EN 1948-1 standard. The wet flue gas was extracted

129 isokinetically with a watercooled titanium probe, passed through an XAD II resin

130 and through a condenser. As earlier research showed that the condensate contains a

131 negligible fraction of the PCDD/Fs, it is not further analysed. The components of 
132 interest adsorbed on XAD II resin, spiked with C-13 labelled PCDD/Fs, PCBs and

133 PAHs of all relevant components, were subsequently determined by an accredited

134 laboratory by GC-MS according to the EN 1948-2 standard. Clean-up for PCDD/Fs

135 was performed using a multi-layer column of modified silica gel, followed by an

136 aluminium oxide and activated carbon column. PCBs were cleaned-up over silica gel

137 and PAHs were cleaned-up online by means of a multi-layer alumina and silica gel

138 column. The detection limits were $0.001 \mathrm{ng}\left(\mathrm{Nm}^{3}\right)^{-1}$ for PCDD/F and dioxin-like

139 PCBs and $0.001 \mu \mathrm{g}\left(\mathrm{Nm}^{3}\right)^{-1}$ for PCBs and PAHs. Part of the extract, obtained during

140 cleaning up, was separated for the determination of HCB by GC-MS according to the

$141 \mathrm{CMA} / 3 / \mathrm{I}$ method (Emis, 2008a). The detection limit was $0.001 \mu \mathrm{g}\left(\mathrm{Nm}^{3}\right)^{-1}$. The

142 accredited laboratory that performed the analyses had to participate regularly in

143 government-organised inter-comparisons in order to demonstrate quality.

144 In the solid residues, PCDD/Fs and dioxin-like PCBs were determined by GC-MS

145 after soxhlet extraction according to the German AbfKlärV, Annex1

146 (Bundesministerium, 2006). The PCBs and HCB were analysed by GC-MS after

147 extraction as described in the CMA/3/I method (Emis, 2008a). The PAHs were

148 analysed by HPLC-UV fluorescence after soxhlet extraction according to the

$149 \mathrm{CMA} / 3 / \mathrm{B}$ method (Emis, 2008b). The detection limits were $1 \mathrm{pg} \mathrm{g}_{\mathrm{dw}}{ }^{-1}$ for PCDD/F, 3

$150 \mathrm{pg} \mathrm{g} \mathrm{dw}^{-1}$ for dioxin-like PCBs, $1 \mathrm{ng} \mathrm{g}_{\mathrm{dw}}{ }^{-1}$ for PCBs and HCB and $10 \mathrm{ng} \mathrm{g}_{\mathrm{dw}}{ }^{-1}$ for

151 PAHs.

152 The ashes were sampled in August 2007 and August 2008 (for PCDD/Fs, PCBs and

153 PAH analysis) and in February 2008 (for HCB analysis); the flue gas was sampled 
154 from the $26^{\text {th }}$ of March until the $9^{\text {th }}$ of April 2008. The concentrations of the POPs in

155 the different output fractions are given in Table 2. For the bottom-, boiler- and filter

156 ashes and for the sludge, the POP concentrations in the two samples (where

157 applicable) are given, the lowest value first.

$158 \quad$ 2.3 Calculation of the amount of POPs in MSW, ASR and incinerator output

159 The mass of a POP “i”" entering the grate furnace ( $\mathrm{POP}_{\mathrm{i}}$ mass $\left._{\text {in }}\right)$ is calculated by

160 multiplying the concentration of that POP given in table $1\left(\mathrm{POP}_{\mathrm{i}}\right.$ concentration $\left.\mathrm{waste}_{\mathrm{j}}\right)$

161 with the mass of the incinerated waste stream "j" (MSW, ASR or WEEE)

162 (mass $\left._{\text {waste,j }}\right)$. The masses of the POP in each of the three waste types are added (see

163 equation 1$)$

$164 \mathrm{POP}_{\mathrm{i}}$ mass $_{\mathrm{in}}=\sum_{j}$ mass $_{\mathrm{wast}, \mathrm{j}} \times \mathrm{POP}_{\mathrm{i}}$ concentraton $_{\text {waste }, \mathrm{j}}$

165 The mass of PCDD/Fs, dioxin-like PCBs, PCBs, and PAHs in the output of the

166 rotary kiln and the grate furnace $\left(\mathrm{POP}_{\mathrm{i}}\right.$ mass $\left._{\text {out }}\right)$ is calculated by multiplying the

167 concentration of the respective POP in the output fraction " $\mathrm{j}$ " (POP

168 concentration $_{\text {output }, \mathrm{j}}$ ) with the mass of that fraction $\left(\right.$ mass $\left._{\text {output }, j}\right)$ given in table 2 . The

169 total is obtained by adding the amount of the POP in each of the output fractions (see

170 equation 2).

$171 \mathrm{POP}_{\mathrm{i}}$ mass $_{\text {out }}=\sum_{j}$ mass $_{\text {ouput }, \mathrm{j}} \times \mathrm{POP}_{\mathrm{i}}$ concentraton $_{\text {output }, \mathrm{j}}$

172 Concentrations below the detection limit are assumed zero in the calculations (see

173 also paragraph 3.4).

\section{$174 \quad 2.4$ POP-weighing methodology}


175 In order to compare the total amount of all POPs (not just the individual POP groups

176 separately) in the in- and output of a waste incinerator, a "weighed POP mass" (POP

177 mass $_{\mathrm{W}}$ ) is obtained for each POP in the input and output, respectively, by multiplying

178 the mass of each POP "i" with a "weighing factor" (see equation 3 below):

$179 \mathrm{POP}_{\mathrm{i}}$ mass $_{\mathrm{W}}=\mathrm{POP}_{\mathrm{i}}$ w eighing factor $\times \sum_{j} \operatorname{mass}_{\mathrm{j}} \times \mathrm{POP}_{\mathrm{i}}$ concentraton $_{\mathrm{j}}$

180 where "mass, ${ }_{j}$ " equals the mass of different waste types (input) or the mass of the

181 different output fractions (flue gas, bottom ash, boiler ash, filter ash or sludge,

182 respectively). A total weighed POP mass (Total POP mass ${ }_{W}$ ) for the in- and output is

183 obtained by adding the weighed POP masses for the different POPs:

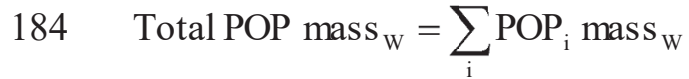

185 The ratio of the total weighed POP mass (equation 5) for the input (Total POP

186 mass $\left._{\mathrm{W}, \text { input }}\right)$ over the total weighed POP mass for the output (Total POP mass $\mathrm{W}_{\text {,output }}$ )

187 indicates whether a waste incinerator acts as a POP sink or source.

188 Ratio $=\frac{\text { Total POP } \text { mass }_{\mathrm{W}, \text { input }}}{\text { Total POP } \text { mas } \mathrm{S}_{\mathrm{W}, \text { output }}}$

189 Even though most of the POPs belong to the group of halogenated organic

190 compounds, they do not necessarily provoke the same health effects, what makes it

191 difficult to compare their toxicity. Furthermore, it is difficult to quantify the severity

192 of the different health effects. (Is, for instance, the suppression of the immune

193 system, making the exposed person more vulnerable to infections, a more or less

194 severe effect than the development of a learning disability?). 
195 The idea of weighing the amount of toxic substances using a toxicity-related

196 parameter was already proposed by Horvath et al. (1995). They described a

197 methodology in which $1 / \mathrm{TLV}^{1}$ is used as a factor to weigh toxic chemicals before

198 adding their masses. The TLV was preferred to other toxicity indices, because it is

199 available for a very broad group of chemicals. Also Davis et al. (1994) presented a

200 model, in which toxic chemical releases are weighed by a factor based on lethal

201 doses for rodents and fish. Hereby only the acute toxicity of the chemicals is taken

202 into account. Forman (1993) developed a chemical index, intended for the ranking of

203 chemical releases, in order to identify facilities estimated to contribute the largest

204 amount of toxic releases to the environment. This chemical index (CI) combines

205 minimal risk doses (MRDs) ${ }^{2}$ with carcinogenic doses calculated from EPA

206 "regulatory risk and hazard levels" and from potency factors ${ }^{3}$.

207 POPs resist well to biological and chemical degradation and are thus stable over time

208 in normal environmental conditions, so chronic rather than acute exposure is the

209 main issue in the situation considered here. Lethal doses, which are a measure for

210 acute toxicity, are not considered advisable as weighing factor. Mato et al. (2007)

211 showed that in Japan, diet accounted for more than $90 \%$ of the intake of PCDD/Fs

212 and dioxin-like PCBs. The fact that food is the primary source of human exposure for

213 most of the POPs is confirmed by toxicological information in the Environmental

\footnotetext{
${ }^{1}$ TLV stands for Threshold Limit Value and is the time weighted average airborne concentration $\left(\mathrm{mg}\left(\mathrm{m}^{3}\right)^{-1}\right)$ for an 8-hour workday and a 40-hour workweek, to which it is believed that nearly all workers may repeatedly be exposed, day after day, for a working lifetime, without adverse effect

${ }^{2}$ MRD stands for Minimal Risk Dose and is the estimate of the amount of a substance, expressed in $\mathrm{mg}\left(\mathrm{kg}_{\text {body }}\right.$ weight.day) ${ }^{-1}$, which can be ingested daily over a lifetime by humans without adverse non cancer health effects

${ }^{3}$ For oral exposure to low doses, there seems to be a linear relationship between cancer risk and dose. The potency factor is the slope of the dose response curve at low doses, expressed in ( $\mathrm{kg}_{\text {body weight }}$.day) $\mathrm{mg}^{-1}$.
} 
214 Health Criteria of the World Health Organization and the Toxicological profiles of

215 the American Agency for Toxic Substances and Disease Registry (ATSDR 1995a;

216 ATSDR 1995b; ATSDR 1998; World Health Organisation, 1998a; World Health

217 Organisation, 1998b; World Health Organisation, 1998c; ATSDR 2000; ATSDR

218 2002a; ATSDR 2002b; ATSDR 2002c; ATSDR 2003; ATSDR 2004; ATSDR 2005).

219 For all these reasons (chronic rather than acute exposure, major uptake by food rather

220 than from air), in the methodology described and applied in this paper, the "minimal

221 risk dose (MRD)" for non-carcinogenic effects of chronic oral exposure to a given

222 POP is preferred to lethal doses and TLVs for weighing. As shown in equation 6, the

223 weighing factor (see equation 3) is set equal to 1/MRD:

$224 \quad \mathrm{POP}_{\mathrm{i}}$ weighing factor $=\frac{1}{\mathrm{MRD}_{\mathrm{i}}}$

225 The methodology must be considered as a pragmatic attempt to answer the question

226 whether a waste incinerator should be considered as an overall sink or source of

227 POPs. It takes into account any adverse effect of the POPs, irrespective of its severity

228 and not one particular effect. Table 3 gives an overview of the MRDs $(\mathrm{mg} / \mathrm{kg}$ body

229 weight.day) selected from literature and applied in this study.

230 PBDE-concentrations are often only reported as a total, without specification of the

231 considered congener(s). For this group of POPs, a maximum and minimum weighed

232 input and output is calculated applying the MRD of octaBDE (lowest MRD) and

233 decaBDE (highest MRD). The same approach is used for PAHs, where the MRD of

234 the most and least toxic of the 16 EPA PAHs are applied. The composition of the

235 chlorinated pesticides incinerated in the rotary kiln selected to illustrate the 
236 methodology (see paragraph 3.1) is not exactly known, so a maximum and minimum

237 is calculated using the MRDs of aldrin (lowest MRD of all 9 Stockholm pesticides)

238 and mirex (highest MRD of all 9 Stockholm pesticides). The comment column in

239 table 3 points out if additional assumptions were made for the application of the

240 mentioned MRDs. Hexachlorobenzene (HCB), which is one of the nine POP

241 pesticides considered by the Stockholm convention, can also be produced during

242 combustion processes and found in the output of waste incinerators (Wienecke et al.,

243 1995). Since the MRD of HCB is of the same order of magnitude as the one of PCBs,

244 its presence can influence the total weighed POP-output significantly.

245 Information from the World Health Organization (WHO-Environmental Health

246 Criteria) and the American Agency for Toxic Substances and Disease Registry

247 (ATSDR-Toxicological profiles) indicates that several of the POPs within the scope

248 of this study are carcinogenic, are possibly carcinogenic or are not classifiable as to

249 their carcinogenecity. Therefore the methodology also attempts to weigh the

250 considered POPs by using the "potency factor" for oral exposure as toxicity factor in 251 equation (3).

$252 \quad$ POP $_{\mathrm{i}}$ weighing factor $=$ Potency factor $_{\mathrm{i}}$

253 Table 4 gives the limited number of potency factors available for the relevant

254 components. The dioxin-like PCB- and PBDD/F-masses expressed in TEQ are

255 weighed using the potency factor of the PCDD/Fs (in TEQ). This approach is

256 proposed by the ATSDR (ATSDR, 1998) and was also used by van Larebeke et al. 257 (2001). 
258 Some PAHs are classified by the International Agency for Research on Cancer as

259 possibly or probably carcinogenic. Therefore, the PAHs in the output are considered

260 in the calculations below. They are weighed using the highest and lowest reported

261 potency factor for benzo(a)pyrene, one of the most carcinogenic PAHs

262 (WHO,1998a). The PAHs in the input are not taken into account, as no data are

263 available on their concentration in the considered types of waste (see also paragraph

264 3.4). For PBDEs no potency factors were found in literature, these pollutants are not

265 considered when POPs are weighed with this factor.

\section{3. Results and discussion}

267 The POPs in the in- and output were compared in the following 3 scenarios:

268 Scenario 1: Incineration of hazardous waste in a BAT compliant rotary kiln

269 - Scenario 2: Incineration of MSW in a BAT compliant grate furnace

270 - Scenario 3: Co-incineration of 3\% plastics of WEEE and 5\% ASR with MSW in

271 a BAT compliant grate furnace

\section{$272 \quad 3.1$ Scenario 1: Incineration of hazardous waste in a rotary kiln}

273 The POPs in the input of the considered rotary kiln are given in paragraph 2.2.1.

274 Table 2 gives the yearly mass flows of the different output fractions, the POP

275 concentration-ranges measured and the POP masses in the different output fractions.

276 The total amount of PCBs in the output fractions of the rotary kiln ( 0.17 to $94 \mathrm{~kg})$ is

$2777.410^{6}$ to $1.310^{4}$ times lower than the yearly PCB input $\left(1.23510^{6} \mathrm{~kg}\right)$. For the other

278 POPs it is not possible to compare the amounts in the in- and output of the rotary kiln 
279 as no detailed information is available on the concentrations in the input as explained

280 in paragraph 2.2.1.

281 A maximum and minimum total weighed in- and output are calculated according to

282 equation 3 using the data given in tables 2, 3 and 4. The PCDD/Fs account for ca. 20

283 to $90 \%$ of the total MRD-weighed output, the dioxin-like PCBs for ca. 10 to $55 \%$,

284 PCBs for ca. 1 to $25 \%$ and $\mathrm{HCB}$ for $<0.1$ to ca. $3 \%$. These percentages take into

285 account the POP concentration ranges in the output fractions and the range on the

286 MRDs used for weighing. The contribution of PAHs is negligible $(<0.1 \%)$. If the

287 POPs in the output are weighed using the cancer potency factors, the PCDD/Fs

288 contribute for ca. 20 to $85 \%$ to the total weighed output, the dioxin-like PCBs for ca.

28910 to $60 \%$ and the PAHs for ca. 5 to $15 \%$.

290 Only ca. $0.6 \%$ of the total amount of weighed POPs in the output of the hazardous

291 waste incinerator is directly emitted in the environment via the flue gas. As

292 mentioned earlier, the POPs in the solid residues are landfilled on specially designed

293 landfills to minimize the environmental impact. If in the output only the POPs in the

294 flue gases are taken into account, the POP input over output ratio equals (7.2 to 7.6)

$29510^{6}$ for MRD-weighing and ca. (1.2 to 4.7) $10^{5}$ for weighing with cancer potency

296 factors (see table 5). If the POPs in all the output fractions are taken in to account,

297 the MRD-weighed POP-input exceeds 3,200 to 49,800 times the output; if the POPs

298 are weighed with potency factors, the input exceeds the output by 890 to 16,900

299 times. The hazardous waste incinerator clearly is a weighed POP sink.

$300 \quad 3.2$ Scenario 2: MSW incineration in a grate furnace 
301 The considered input for the BAT grate furnace selected to illustrate scenario 2 and 3

302 consists of 408,430 tons/year of MSW. A minimum and maximum POP input mass

303 was calculated according to equation 1, using the concentration ranges given in table

304 1. For PCDD/Fs, the estimated yearly PCDD/F input ranges from (0.32 to 2.1$) 10^{-2}$

$305 \mathrm{~kg}$ TEQ; for PCBs it ranges from 3.4 to $13.5 \mathrm{~kg}$. The minimum and maximum

306 amounts of PCDD/Fs, dioxin-like PCBs, PCBs, PAHs and HCBs in the output were

307 calculated according to equation 2 and using the concentration ranges and mass flow

308 data given in table 2. Only ca. $0.4 \%$ of the total amount of PCDD/Fs in the output of

309 the BAT compliant grate furnace come directly in the environment via the flue gas or

310 via the bottom ash granulates used as secondary material. As mentioned earlier, the

311 POPs in the other residues are landfilled in landfills specially designed to minimize

312 environmental impact. The amount of $\mathrm{PCDD} / \mathrm{F}$ in the flue gas and granulates (5.02

$31310^{-5} \mathrm{~kg}$ TEQ) is ca. 60 to 400 times lower than the estimated amount of PCDD/Fs in

314 incinerated waste. When the total PCDD/F output ((1.35 to 1.83$) 10^{-2} \mathrm{~kg}$ TEQ) is

315 compared to the amount of PCDD/Fs in the input, it seems that the grate furnace

316 incinerating MSW can be a sink or source of these POPs, depending on the

317 concentrations in the input waste. For the PCBs, the comparison shows that the

318 amount of these persistent pollutants are ca. 10.000 times lower in the output if the

319 highest concentrations in the waste and the lowest concentrations in the output

320 fractions are considered. (The flue gas and granulates are not considered separately

321 as the latter contain more than $99 \%$ of the total PCB output.) On the other hand, the

322 output could be ca. 2 times higher than the input if the lowest concentrations in the 
323 waste and the highest concentrations in the output fractions are considered. For

324 dioxin-like $\mathrm{PCBs}, \mathrm{PAH}$ and $\mathrm{HCB}$, no representative input concentration data were

325 found and hence no comparison between in- and output can be made.

326 As for the rotary kiln in scenario 1, the minimum and maximum total weighed in-

327 and output for the grate furnace described in paragraph 2.1 are calculated according

328 to equation 3 using the data given in tables 1, 2, 3 and 4. The main contributors to the

329 total MRD-weighed input are the PCDD/Fs (ca. 50\%) and the PBDEs (ca. 25 to

$33050 \%$ ). The contribution of the PBDD/Fs reaches ca. 25\% if the highest

331 concentrations for these POPs given in table 1 are used in the calculations. In case of

332 weighing with cancer potency factors, PAH become the main contributors (ca. 30 to

$33390 \%$ ) but PCDD/Fs and PBDD/Fs remain important (ca. 10 to $45 \%$ and $<0.1 \%$ to ca.

$33425 \%$, repectively). MSW contains ca. $0.35 \%$ plastics of WEEE (Tange and

335 Drohmann, 2005). For the weighing of total PBDD/Fs in this waste fraction, no

336 specific weighing factors were found in literature. In order to apply the MRD for

337 PCDD/Fs as suggested by the World Health Organisation (WHO, 1998b), TEQ-

338 concentrations were estimated. The lowest values (see table 1), which express total

339 PBDD and PBDF concentrations, were reported by Vehlow et al. (2002) without

340 indication of the individual congeners concentration, making it impossible to convert

341 them to TEQ using TEF-values. Sakai et al. (2001) and Abad et al. (2002) reported

$342 \mathrm{PCDD} / \mathrm{F}$ concentrations in waste in both mass and TEQ, the former being on average

343200 times higher than the latter. The minimum PBDD/F mass concentrations given in

344 table 1 were estimated in TEQ by dividing them by this factor. Hereby it is assumed 
345 that the congener distribution of the PBDD/F is similar to the one of PCDD/F. The

$346 \mathrm{PBDD} / \mathrm{F}$ concentration used to calculate the maximum weighed output (see table 1)

347 was reported as the total mass of 8 congeners and isomers, without indication of the

348 individual concentrations (Schlummer et al., 2007). It was multiplied with the

349 average TEF value of the 8 chlorinated analogues to give a PBDD/F concentration in

350 TEQ. The estimation of PBDD/F-concentrations in TEQ introduces an additional

351 uncertainty but it was considered important to include these pollutants, which are

352 considered to have the same MRD and potency factor than PCDD/Fs (WHO, 1998b).

353 Only PCDD/Fs and PCBs contribute significantly to the total MRD-weighed output

354 (ca. 80 to $98 \%$ and 2 to $20 \%$ respectively). If potency factors are used for weighing,

355 the PCDD/Fs, dioxin-like PCBs and PAHs account for ca. 65 to $85 \%$, ca. 2 to $20 \%$

356 and ca. 10 tot $20 \%$ of the total weighed output, respectively. The contribution of

357 HCB is negligible $(<0.1 \%)$.

358 If in the output only the POPs in the flue gases and the granulates are taken into

359 account, the input over output ratios in table 5 indicate that the incinerator clearly

360 acts as a weighed POP sink, both in case of weighing with MRDs and potency

361 factors. If the POPs in all the output fractions are considered, the weighed POP-input

362 is comparable to the weighed POP-output (see table 5). Abad et al. (2000, 2002),

363 Giugliano et al. (2002) and Grosso et al. (2007) came to a similar conclusion for

$364 \mathrm{PCDD} / \mathrm{Fs}$ in MSW incinerators. This can be explained by the fact that PCDD/Fs are

365 one of the main contributors to the total weighed in- and output, as indicated earlier. 


\section{3.3. Co-incineration of 3\% plastics from WEEE and 5\% ASR with MSW in a}

\section{7 grate furnace}

368 Plastics have become an increasingly important part of E\&E equipment: the average

369 proportion has increased from $12 \%$ in 1980 to more than $20 \%$ today (Vehlow et al.,

370 2002; Schlummer et al., 2007). Selective treatment and recycling of WEEE is

371 foreseen in the European Directive 2002/96/EC. One of the components that have to

372 be removed before recycling according to annex II of this directive are plastics

373 containing brominated flame retardants. Increasing amounts of high calorific waste

374 plastics containing high levels of brominated flame retardants become thus available

375 (Schlummer et al., 2007). By co-combusting these plastics in a BAT compliant MSW

376 incinerator, the hazardous POPs they contain are destroyed and energy from these

377 high calorific wastes is recovered. Table 1 gives the concentration ranges of POPs in

378 plastics of WEEE used to calculate the maximum and minimum POP input flow for

379 scenario 3.

380 Another industrial waste stream that can be co-incinerated in grate furnaces is

381 Automotive Shredder Residue (ASR) (Mark et al., 1998; Aae Redin et al., 2001).

382 After dismantling, end-of-life vehicles are shredded and metals, representing 75 to

$38380 \%$ of the mixed waste, are recovered. The remaining $20-25 \%$ is referred to as ASR

384 and is a heterogeneous mixture of both inert and combustible materials, including

385 plastics, glass, fabric, wood, rubber, fibres and paper. About $50 \%$ of the ASR is

386 combustible. Table 1 gives the concentration ranges of POPs in ASR used to

387 calculate the maximum and minimum POP input flow for scenario 3. 
388 In scenario 3 it is assumed that $3 \%$ of the 408,430 tons of MSW yearly incinerated in

389 the grate furnace (scenario 2) would consist of plastics of WEEE, and 5\% of ASR.

390 These percentages are chosen somewhat arbitrarily, but are below the reported

391 maximum workable percentages (Vehlow et al., 1997; Mark et al., 1998; Aae Redin

392 et al., 2001; Vehlow et al., 2002). For PCDD/Fs, the estimated yearly input ranges

393 from (0.83 to 2.6) $10^{-2} \mathrm{~kg}$ TEQ; for PCBs it ranges from 27 to $1,300 \mathrm{~kg}$.

394 The considered POP concentrations in the different output fractions of the grate

395 furnace are the same as in scenario 2 (see table 2) as it is assumed that the incoming

396 POPs are completely destroyed and the formation of POPs in the outputs only

397 depends on process-conditions. This assumption is supported by a recent study by

398 Van Caneghem et al. (2009) where POP-concentrations in the different in- and

399 output fractions of a fluidised bed combustor were compared during normal

400 operation (input consisting of $30 \%$ waste water treatment sludge and $70 \%$ RDF) and

401 during co-incineration of automotive shredder residue (input consisting of $25 \%$ ASR,

$40225 \%$ RDF, $50 \%$ waste water treatment sludge). Because of the high concentration of

403 POPs in the ASR, the total weighed POP input was on average 16 times higher when

404 this waste was co-incinerated. Nevertheless it was observed that the weighed POP

405 output did not change significantly. So, although the assumption is supported by

406 indirect evidence, the confidence of the results for this scenario is somewhat lower

407 than for scenario 1 and 2. When the yearly amount of PCDD/F in the output given in

408 table 2 is compared to the amount of PCDD/Fs in the input, it seems that the grate

409 furnace incinerating MSW, WEEE and ASR can be a sink or source of these POPs, 
410 depending on the assumptions made on the concentrations in the wastes. The mass of

411 PCBs in the input, mainly coming from the plastics of WEEE and ASR, is estimated

412 ca. 20 to 100 times higher than in the output.

413 The main contributors to the MRD-weighed input are the PBDEs from the plastics of

414 WEEE (ca. 40 to $70 \%$ ), PCDD/Fs (ca. 10 to 20\%), PCBs (ca. 5 to 20\%) and

$415 \mathrm{PBDD} / \mathrm{Fs}(<0.1 \%$ to ca. $40 \%)$. If potency factors are used for weighing, the main

416 contributors are PAHs (ca. 10 to $60 \%), \mathrm{PBDD} / \mathrm{Fs}(<0.1 \%$ to ca. $60 \%$ ) and DEHP

417 (ca. 10 to 30\%). PCDD/Fs (ca. 14\%) and PCBs (ca. 1 to 10\%) are less important.

418 The input over output ratios given in table 5 indicate that when WEEE-plastics (3\%)

419 and ASR (5\%) are co-combusted, the MSW incinerator acts as weighed POP sink.

\section{3.4. Influence of output concentrations below detection limit}

421 In the calculation of the ratios discussed in paragraph 3, in the output fractions all

422 POP-concentrations below the detection limit were assumed zero. Because of this

423 assumption, the total (weighed) POP output may be underestimated. To investigate

424 the impact of this assumption, the input over output ratios were recalculated with all

425 the output concentrations below the detection limit taken equal to the detection limit.

426 If e.g. the detection limit for the individual PAHs was $10 \mathrm{ng} / \mathrm{g}_{\mathrm{dw}}$ and the

427 concentration of all of the 16 analysed PAH was below this limit, total PAH-

428 concentration was taken $160 \mathrm{ng} / \mathrm{g}_{\mathrm{dw}}$. This had no significant influence $(<5 \%$

429 decrease) on the minimum input over output ratios of the rotary kiln and the

430 conclusions drawn in paragraph 3.1 remain valid. For the grate furnace, increasing

431 the non-detectable PCDD/F, dioxin-like PCB, PCB and HCB concentrations also 
432 was of limited influence $(<15 \%$ decrease in minimum input over output ratio).

433 However, if in the output only the POPs in the flue gas and granulate fraction were

434 taken into account, setting the non detectable PAH-concentrations equal to the

435 detection limit decreased the minimum input over output ratios by ca. a factor 2 . This

436 decrease of the input over output ratio does however not alter the conclusions drawn

437 in paragraphs 3.2 and 3.3. Furthermore, the PAHs in the input were taken equal to

438 zero in the calculations, because although several data were found, they could not be

439 considered sufficiently representative. Ruokojärvi et al. (1995) reported a PAH-

440 concentration of $2.0 \mu \mathrm{g} \mathrm{g}_{\mathrm{dw}}{ }^{-1}$ on household waste in a Finish landfill. The waste was,

441 however, sampled close to a controlled fire, which could have influenced the PAH

442 concentration although the waste itself was not burned. Moeller and Reeh (2003)

443 reported a PAH concentration of $1.2 \mu \mathrm{g} \mathrm{g}_{\mathrm{dw}}{ }^{-1}$ for composted Danish MSW. Brändli et

444 al. (2007) reported PAH-concentration of $3.32 \mu \mathrm{g} \mathrm{g}_{\mathrm{dw}}{ }^{-1}, 0.41 \mu \mathrm{g} \mathrm{g}_{\mathrm{dw}}{ }^{-1}$ and $1.45 \mu \mathrm{g} \mathrm{g}_{\mathrm{dw}}{ }^{-}$

$445{ }^{1}$ for Swiss green waste, a mixture of green and organic kitchen waste and digested

446 green- and kitchen waste, respectively (ca 40\% of he MSW incinerated in the grate

447 furnace used to illustrate the methodology in paragraph 3.2 and 3.2 consists of

448 organic kitchen waste and green waste). Li et al. reported PAH output over input

449 ratios ranging from 0.00018 to 0.00032 for the incineration of waste plastics (Li et

450 al., 2001). If in scenario 2 (see paragraph 3.2), the PAH-concentration of MSW is

451 taken equal to $2.0 \mu \mathrm{g} \mathrm{g}_{\mathrm{dw}}{ }^{-1}$ (Ruokojärvi et al., 1995), this has a negligible influence

452 on the MRD-weighed POP-input, but a significant influence on the POP-input

453 weighed with cancer potency factors: the minimum input over output ratio which 
454 ranged from 0.1 to 6 (see table 5) increases to a range of 1.4 to 70 . This indicated that

455 accurate PAH concentrations in the input would be required.

\section{4. Conclusion}

457 The amount of different POPs was compared in the in- and outputs of a BAT

458 compliant rotary kiln incinerating hazardous waste, a BAT compliant grate furnace

459 incinerating MSW and the same grate furnace co-incinerating WEEE and ASR with

460 MSW. In order to compare the total amount of POPs, a methodology was developed

461 to weigh the POPs, in the in- and output of waste incinerators based on MRDs or

462 cancer potency factors.

463 The mass of PCBs incinerated in the rotary kiln exceeded $7.410^{6}$ to $1.310^{4}$ times the

464 mass of PCBs found in the output: the incinerator was clearly a sink of PCBs. For the

465 other POPs it was not possible to compare the amounts in the in- and output, as no

466 detailed information was available on the concentrations in the input. PCDD/Fs and

467 dioxin-like PCBs were the main contributors to the MRD-weighed output. If potency

468 factors were used for weighing, also PAH became important contributors. The total

469 amount of weighed POPs in the input waste exceeded, depending on input and

470 process-conditions and applied weighing factor, $1.210^{5}$ to $7.610^{6}$ times the amount

471 of weighed POPs emitted in the environment via the flue gas. If the POPs in all

472 output fractions were taken into account, the weighed POP input over output ratio

473 ranged from 890 to 49,800 . The studied rotary kiln incinerating hazardous waste was

474 clearly a sink of POPs. 
475 For the grate furnace incinerating MSW, the mass of PCDD/Fs in the flue gas and

476 granulates was ca. 60 to 400 times lower than the PCDD/Fs mass in the incinerated

477 waste, depending on the considered concentrations. When the total amount of

$478 \mathrm{PCDD} / \mathrm{F}$ in the output was compared to the amount of PCDD/Fs in the input waste, it

479 seemed that the grate furnace incinerating MSW could be a sink or source of these

480 POPs, but the difference between output and input is rather limited. Also for PCBs

481 the grate furnace incinerating MSW could be a sink or source depending on the

482 considered concentrations in the input waste and in the output. PCDD/Fs, PBDD/Fs

483 and PBDEs were the most important contributors to the MRD-weighed input. In case

484 of weighing with cancer potency factors, PAH become the main contributors. The

485 weighed POP input over output ratio ranged from 6 to 580 depending on the

486 considered concentrations and weighing factors. The total amount of weighed POPs

487 in the output (all fractions) was about the same as in the input. The conclusion was

488 the same as for the (un-weighed) PCDD/Fs and PCBs.

489 When $5 \%$ of ASR and $3 \%$ of plastics of WEEE would be co-incinerated in the BAT

490 compliant grate furnace incinerating MSW, the mass of PCBs in the input, mainly

491 from the WEEE and ASR, would be estimated ca. 20 to 100 times higher than the

492 mass of PCBs in the output. The PBDE's from the plastics of WEEE would become

493 the main contributors to the MRD-weighed input. The weighed input over output

494 (flue gases and granulates) ratio would range from 50 to 4,100 depending on the

495 considered concentrations and weighing factors. If all the POPs in the output were

496 taken into account, the input over output ratio would range from 1.0 to 23 . Both the 
497 comparison of PCBs and total weighed POP masses in the in- and output showed

498 that, when wastes containing relatively high levels of POPs are co-incinerated with

499 MSW, the BAT compliant grate furnaces studied acted as a PCB and weighed POP

500 sink.

501 Acknowledgements

502 Grateful acknowledgement is made to M. Jaspers (Indaver NV), H. Veulemans

503 (University of Leuven, Department of Environmental Health) and L. Hens

504 (University of Brussels, Department of Human Ecology) for providing useful

505 information and A. Covaci (University of Antwerp, Department of Pharmaceutical

506 Science) for critical review.

507

508 References

509 Aae Redin L., Hjelt M., Marklund S., 2001. Co-combustion of shredder residues and

510 municipal solid waste in a Swedish municipal solid waste incinerator. Waste

511 Manage. Res. 19, 518-525

512 Abad E., Adrados A., Caixach J., Fabrellas B., Rivera J., 2000. Dioxin mass balance

513 in a municipal waste incinerator. Chemosphere 40, 1143-1147

514 Abad E., Adrados A., Caixach J., Rivera J., 2002. Dioxin abatement strategies and

515 mass balance at a municipal waste management plant. Environ. Sci. Technol. 36, 92-

51699

517 Agency of Toxic Substances and Disease Registry (ATSDR), 1995a. Toxicological

518 Profile for Mirex and Chlordecone 
519 Agency of Toxic Substances and Disease Registry (ATSDR), 1995b. Toxicological

520 Profile for Polycyclic Aromatic Hydrocarbons

521 Agency of Toxic Substances and Disease Registry (ATSDR), 1998. Toxicological

522 Profile for Chlorinated Dibenzo-p-dioxins (CDDs)

523 Agency of Toxic Substances and Disease Registry (ATSDR), 2000. Toxicological

524 Profile for Polychlorinated Biphenyls (PCBs)

525 Agency of Toxic Substances and Disease Registry (ATSDR), 2002a. Toxicological

526 Profile for Di(2-ethylhexyl)phthalate (DEHP)

527 Agency of Toxic Substances and Disease Registry (ATSDR), 2002b. Toxicological

528 Profile for Hexachlorobenzene

529 Agency of Toxic Substances and Disease Registry (ATSDR), 2002c. Toxicological

530 Profile for DDT, DDE, and DDD

531 Agency of Toxic Substances and Disease Registry (ATSDR), 2003. Toxicological

532 Profile for Aldrin / Dieldrin

533 Agency of Toxic Substances and Disease Registry (ATSDR), 2004. Toxicological

534 Profile for Polybrominated biphenyls / polybrominated diphenyl ethers

535 Agency of Toxic Substances and Disease Registry (ATSDR), 2005. Toxicological

536 Profile for Naphtalene / 1-Methylnaphtalene / 2-Methylnaphtalene

537 Brändli R., Bucheli T., Kupper T., Mayer J., Stadelmann F., Tarradellas J., 2007.

538 Fate of PCBs, PAHs and their source characteristic ratios during composting and

539 digestion of source-separated organic waste in full-scale plants. Environ. Pollut. 148, $540 \quad 520-528$ 
541 Bundesministerium fur Umwelt, Naturschutz und Reaktorsicherheit, 2006.

542 Ordinance on Waste and Sewage Sludge (AbfklärV). Annex 1: Sampling, Sample

543 Preparation and Analysis of Sludge and Soil.

544 Davis G., Kincaid 1., Swanson M., Schultz T., Bartmess J., Griffith B., Jones S.,

545 1994. Chemical Hazard Evaluation for Management Strategies: A Method for

546 Ranking and Scoring Chemicals by Potential Human Health and Environmental

547 Impacts. Environmental Protection Agency (EPA/600/R-94/177)

548 Emis, 2008a. Compendium for Sampling and Analysis (CMA). Method CMA/3/I:

549 Organic Chlorinated Pesticides, PCBs and Higher Chlorinated Benzenes (in Dutch).

$550 \quad$ (Available via

551 http://www.emis.vito.be/EMIS/Media/referentielabo_bodem_CMA_2007 3-I.pdf)

552 Emis, 2008b. Compendium for Sampling and Analysis (CMA). Method CMA/3/B:

553 Polycyclic Aromatic Hydrocarbons (in Dutch). (Available via

554 http://www.emis.vito.be/EMIS/Media/referentielabo_bodem_CMA_2007_3-B.pdf)

555 Everaert K., Baeyens J., 2002. The formation and emission of dioxins in large scale

556 thermal processes. Chemosphere 46, 439-448

557 Forman D., 1993. Chemical Indexing System for The Toxic Chemical Release

558 Inventory Part I: Chronic Index. Environmental Protection Agency (EPA/903/R-

559 93/002)

560 Giugliano M., Cernuschi S., Grosso M., Miglio R., Aloigi E., 2002. PCDD/F mass

561 balance in the flue gas cleaning units of a MSW incineration plant. Chemosphere 46, $562 \quad 1321-1328$ 
563 Grosso M., Cernuschi S., Giugliano M., Lonati G., Rigamonti L., 2007.

564 Environmental release and mass flux partitioning of PCDD/Fs during normal and

565 transient operation of full scale waste to energy plants. Chemosphere 67, S118-S124

566 Hedman B., Burvall J., Nilsson C., Marklund S., 2007. PCDD/F in source-sorted

567 fractions and emissions from their co-combustion with reed canary-grass. Waste

568 Manage. 27, 1580-1592

569 Horvath A., Hendrickson C.T., Lave L.B., McMichael F.C., Wu T., 1995. Toxic

570 emissions indices for green design and inventory. Environ. Sci. Technol. 29, 86A-

$57190 \mathrm{~A}$

572 Ishikawa Y., Noma Y., Mori Y., Sakai S., 2007. Congener profiles of PCB and a

573 proposed new set of indicator congeners, Chemosphere 67, 1838-1851

574 Li C., Zhuang, H., Hsieh L., Lee W., Tsao, M, 2001. PAH emission from the

575 incineration of three plastic wastes. Environ. Int. 71, 61-67

576 Mark F., Fischer M., Smith K., 1998. Energy Recovery from Automotive Shredder

577 Residue through Co-combustion with Municipal Solid Waste. PlasticsEurope

578 Technical Report 8026

579 Mato Y., Suzuki N., Katatani N., Kadokami K., Nakano T., Nakayama S., Sekii H.,

580 Komoto S., Miyake S., Morita M, 2007. Human intake of PCDDs, PCDFs and dioxin

581 like PCBs in Japan 2001 and 2002. Chemosphere 67, S247-S255

582 McKay G., 2002. Dioxin characterisation, formation and minimisation during

583 municipal solid waste (MSW) incineration: review. Chem. Eng. J. 86, 343-368 
584 Moeller J., Reeh U., 2003. Degradation of DEPH, PAHs and LAS in source

585 separated MSW and sewage sludge during composting. Compost Sci. Util. 11, 370-

$586 \quad 378$

587 Morf L., Tremp J., Gloor R., Schuppisser F., Stengele M., Taverna R., 2007. Metals, 588 non-metals and PCB in electrical an electronic waste - Actual levels in Switzerland,

589 Waste Manage. 27, 1306-1316

590 Ruokojärvi P., Ruuskanen J., Ettala M., Rahkonen P., Tarhanen J., 1995. Formation

591 of polyaromatic hydrocarbons and polychlorinated organic compounds in municipal

592 waste landfill fires. Chemosphere 8, 3899-3908

593 Sakai S., Takatsuki H., Urano S., 1998. Leaching behaviour of persistent organic

594 pollutants in shredder residues. Chemosphere 37, 2047-2054

595 Sakai S., Ukai T., Takatsuki H., Nakamura K., Kinoshita S., Takasuga T., 1999.

596 Substance flow analysis of coplanar PCBs released from waste incineration

597 processes. J. Master Cycles Waste Manag. 1, 62-74

598 Sakai S., Hayakawa K., Takatsuki H., Kawakami I., 2001. Dioxin-like PCBs released

599 from waste incineration and their deposition flux. Environ. Sci. Technol. 35, 3601-

$600 \quad 3607$

601 Schlummer M., Gruber L., Märer A., Wolz G., van Eldik R., 2007. Characterisation

602 of polymer fractions from electrical and electronic equipment (WEEE) and

603 implications for waste management. Chemosphere 67, 1866-1876 
604 Tange L., Drohmann D., 2005. Waste electrical and electronic equipment plastics

605 with brominated flame retardants - from legislation to separate treatment - thermal

606 processes. Polym. Degrad. Stabil. 88, 35-40

607 Van Caneghem J., Block C., Van Brecht A., Wauters G. and Vandecasteele C., 2009.

608 Influence of co-incinerating ASR on the mass balance for POPs in a fluidised bed

609 combustor. Publication in preparation.

610 Vandecasteele C., Wauters G., Arickx S., Jaspers M., Van Gerven T., 2007.

611 Integrated municipal solid waste treatment using a grate furnace incinerator: The

612 Indaver case. Waste Manage. 27, 1366-1375

613 Van Laerebeke N., Hens L., Schepens P., Covaci A., Baeyens J., Everaert K.,

614 Bernheim J., Vlietinck R., De Poorter G., 2001. The Belgian PCB and dioxin

615 incident of January-June 1999: exposure data and potential impact on health.

616 Environ. Health Persp. 109, 265-273

617 Vehlow J., Mark F.E., 1997. Electrical and Electronic Plastics Waste Co-combustion

618 with Municipal Solid Waste for Energy Recovery. PlasticsEurope Technical Report

6198020

620 Vehlow J., Bergfeldt B., Hunsinger H., Jay K., Mark F.E., Tange L., Drohmann D.,

621 Fish H., 2002. Recycling of Bromine from Plastics Containing Brominated Flame

622 Retardants in State-of-the-art Combustion Facilities. PlasticsEurope Technical

623 Report 8040

624 Wienecke J., Kruse H., Huckfeldt U., Eickhoff W., Wassermann O., 1995. Organic 
625 compounds in the flue gas of hazardous waste incinerator. Chemosphere 30, 907-

626913.

627 Wilken L., Cornelsen B., Zeschmar-Lahl B., Jager J.,1992. Distribution of

$628 \mathrm{PCDD} / \mathrm{PCDF}$ and other organochlorine compounds in different municipal solid

629 waste fractions. Chemosphere 25, 1517-1523

630 World Health Organisation (WHO), 1998a. Assessment Of The Health Risk Of

631 Dioxins: Re-evaluation of The Tolerable Daily Intake (TDI). Geneva, Switzerland.

632 World Health Organisation (WHO), 1998b. Environmental Health Criteria 205

633 World Health Organisation (WHO), 1998c. Environmental Health Criteria 202 
Table 1: POP concentration ranges in waste incinerated in the BAT compliant grate furnace

\begin{tabular}{|c|c|c|c|c|}
\hline & \multicolumn{2}{|c|}{ Concentration } & & \multirow{3}{*}{ Comments } \\
\hline & Min. & Max. & & \\
\hline \multicolumn{4}{|c|}{ MSW } & \\
\hline $\mathrm{PCBs}$ & 8.2 & 33.0 & $\mu \mathrm{g} \mathrm{kg}^{-1}$ & $\begin{array}{l}\text { Measured PCB concentrations in Japanese waste (Sakai et } \\
\text { al., 1999, Sakai et al., 2001, Ishikawa et al., 2007) }\end{array}$ \\
\hline $\mathrm{PCDD} / \mathrm{Fs}$ & 7.91 & 50.2 & ng TEQ kg ${ }^{-1}$ & $\begin{array}{l}\text { The minimum value is the average concentration in } 18 \\
\text { Spanish waste samples analysed in } 2000 \text { (Abad et al., } \\
\text { 2002). The maximum value is the average concentration in } \\
\text { German samples taken in } 1980 \text { (Wilken et al., 1992) }\end{array}$ \\
\hline $\begin{array}{l}\text { WEEE-plastics in } \\
\text { MSW }\end{array}$ & & & $\%$ & Tange and Drohmann, 2005 \\
\hline \multicolumn{5}{|c|}{ Plastics of Waste of Electrical and Electronic Equipment (WEEE) } \\
\hline Br content & & & 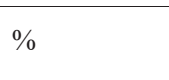 & $\begin{array}{l}\text { Average Br-concentration of mixed shredded WEEE- } \\
\text { plastics (Schlummer et al., 2007) }\end{array}$ \\
\hline PCB & 0.09 & 0.15 & $\mathrm{mg} \mathrm{kg}^{-1}$ & Morf et al., 2007 \\
\hline PBDD & 15 & 7,700 & $\mathrm{ng} \mathrm{kg}^{-1}$ & $\begin{array}{l}\text { Lowest value reported by Vehlow et al., } 2002 \\
\text { Highest value reported by Schlummer et al., } 2007\end{array}$ \\
\hline PBDF & 600 & 7,700 & $\mathrm{ng} \mathrm{kg}^{-1}$ & $\begin{array}{l}\text { Lowest value reported by Vehlow et al., } 2002 \\
\text { Highest value reported by Schlummer et al., } 2007\end{array}$ \\
\hline \multicolumn{5}{|c|}{ Automotive Shredder Residues (ASR) } \\
\hline $\mathrm{PCBs}$ & 1.1 & 63 & $\mathrm{mg} \mathrm{kg}^{-1}$ & $\begin{array}{l}\text { Lowest value reported by Aae Redin et al., } 2001 \\
\text { Highest value reported by Mark et al., } 1998\end{array}$ \\
\hline $\mathrm{PCDD} / \mathrm{Fs}$ & & & ng TEQ $\mathrm{kg}^{-1}$ & Sakai et al., 1998 (Japanese ASR) \\
\hline DEHP & & 000 & $\mathrm{mg} \mathrm{kg}^{-1}$ & Sakai et al., 1998 (Japanese ASR) \\
\hline
\end{tabular}


Table 2

Click here to download Table: Table 2 - rev3.doc

Table 2: POP concentrations in the output fractions of the considered waste incinerators

\begin{tabular}{|c|c|c|c|c|c|c|}
\hline & $\begin{array}{l}\text { PCDD/Fs } \\
\text { pg TEQ } g_{d w}^{-1}\end{array}$ & 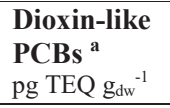 & $n g g_{d w}{ }^{-1}$ & $\begin{array}{l}\text { PAH } \\
\operatorname{ng~g}_{d w}{ }^{-1}\end{array}$ & ng $g_{d w}{ }^{-1}$ & $\begin{array}{l}\text { Mass flow } \\
\text { ton }_{\mathrm{dw}} \text { year }^{-1}\end{array}$ \\
\hline \multicolumn{7}{|c|}{ Scenario 1 (Rotary kiln) } \\
\hline Flue gas & $10^{\mathrm{d}}$ & n.d. & $41^{\mathrm{e}}$ & $1,710^{\mathrm{e}}$ & $0.48^{\mathrm{e}}$ & $713,014^{\mathrm{f}}$ \\
\hline Bottom ash & $12-71$ & $4.0-483$ & $5.5-4,200$ & $79-1,400$ & 91 & 22,126 \\
\hline Boiler ash & $73-161$ & $10.4-11.3$ & n.d. -7.4 & n.d. & 20 & 683 \\
\hline Filter ash & $246-733$ & $0.12-48$ & n.d. -4.5 & n.d. - 22 & 12 & 1,829 \\
\hline Sludge & $333-371$ & $0.2-9.7$ & $8.5-830$ & n.d. - 210 & 110 & 3,246 \\
\hline $\begin{array}{l}\text { Total output } \\
\left(\mathrm{kg}_{\text {year }}{ }^{-1}\right)\end{array}$ & $\begin{array}{l}(1.14- \\
3.63) 10^{-3 \mathrm{~g}}\end{array}$ & $\begin{array}{l}(1.16-108) \\
10^{-4} \mathrm{~g}\end{array}$ & $0.17-94$ & $2.96-32.6$ & 2.26 & \\
\hline \multicolumn{7}{|c|}{ Scenario 2 and 3 (Grate furnace) } \\
\hline Flue gas & $20^{\mathrm{d}}$ & $3^{d}$ & $13^{\mathrm{e}}$ & $4,950^{\mathrm{e}}$ & $0.034^{\mathrm{e}}$ & $2,115,376^{\mathrm{f}}$ \\
\hline Bottom ash & $8.1-22$ & $1.3-47$ & n.d. -6.2 & $570-680$ & n.d. & 94,724 \\
\hline Granulate fraction & 0.58 & 0.56 & n.d. & 220 & n.d. & 31,723 \\
\hline Boiler ash & $37-97$ & $0.007-2.9$ & n.d. & n.d. & n.d. & 8,660 \\
\hline $\begin{array}{l}\text { Flue gas cleaning } \\
\text { residue }\end{array}$ & $\begin{array}{l}1,040- \\
1,290\end{array}$ & $17-29$ & n.d. & n.d. -24 & n.d. & 11,939 \\
\hline $\begin{array}{l}\text { Total output } \\
\left(\mathrm{kg} \mathrm{year}^{-1}\right)\end{array}$ & $\begin{array}{l}(1.35- \\
1.83) 10^{-2 \mathrm{~g}}\end{array}$ & $\begin{array}{l}(3.29- \\
48.3) 10^{-4 \mathrm{~g}}\end{array}$ & $(0.028-6.2)$ & $65-75$ & $7.1910^{-5}$ & \\
\hline $\begin{array}{l}{ }^{\mathrm{a}} \text { sum of PCB } 77, \text { PCB } 8 \\
\text { PCB } 169, \text { PCB } 189 \\
\text { b sum of PCB 28, PCB } \\
{ }^{c} \text { sum of } 16 \text { EPA } \\
\text { d expressed in pg TEQ } \\
\text { e expressed in ng }\left(\mathrm{Nm}^{3}\right) \\
\text { f expressed in kNm }{ }^{3} \text { yea } \\
\text { g expressed in kg TEQ y } \\
\text { n.d. : concentration belo }\end{array}$ & $\begin{array}{l}\text { 2, PCB 105, PC } \\
\left.\mathrm{Nm}^{3}\right)^{-1} \\
\text { ear }^{-1} \\
\text { w the detection }\end{array}$ & $\begin{array}{l}\text { B } 114, \text { PCB } 11 \\
\text { B } 118, \text { PCB } 1\end{array}$ & $\begin{array}{l}8, \text { PCB } 123, \text { P } \\
38, \text { PCB } 153, \text { P }\end{array}$ & $\begin{array}{l}\mathrm{B} 126, \text { PCB } 1 \\
\text { CB } 180\end{array}$ & 6, PCB 157, & CB 167, \\
\hline
\end{tabular}


Table 3: MRDs used for the calculation of weighed POP masses

\begin{tabular}{|c|c|c|}
\hline & $\begin{array}{l}\text { MRD }^{\mathrm{a}} \\
\mathrm{mg}(\mathrm{kg} \text { bw.day })^{-1}\end{array}$ & Comments \\
\hline $\begin{array}{l}\mathrm{PCDD} / \mathrm{Fs} \\
\text { Dioxin-like PCBs } \\
\mathrm{PBDD} / \mathrm{Fs}\end{array}$ & 1. $10^{-9} \mathrm{TEQ}$ & $\begin{array}{l}\mathrm{TDI}^{\mathrm{d}} \text { for dioxin-like compounds with TEF-values (WHO, } \\
\text { 1998a) } \\
\text { Sufficient data supports the concept of using corresponding } \\
\text { TEF values for brominated and chlorinated analogues } \\
\text { (WHO, 1998b) }\end{array}$ \\
\hline PCBs & $2.10^{-5}$ & $\begin{array}{l}\mathrm{MRL}^{\mathrm{c}} \text { for chronic oral exposure to Aroclor } 1254 \text { (ATSDR, } \\
2000 \text { ) }\end{array}$ \\
\hline \multirow{2}{*}{ Chlorinated pesticides } & 3. $10^{-5}$ & $\mathrm{MRL}^{\mathrm{c}}$ for chronic oral exposure to aldrin (ATSDR, 2003) \\
\hline & $8.10^{-4}$ & $M^{M R L}{ }^{c}$ for chronic oral exposure to mirex (ATSDR, 1995a) \\
\hline \multirow{2}{*}{ PAHs } & 2. $10^{-2}$ & $\mathrm{RfD}^{\mathrm{b}}$ for naphthalene (ATSDR, 2005) \\
\hline & 3. $10^{-1}$ & $\mathrm{RfD}^{\mathrm{b}}$ for anthracene (ATSDR, 1995b) \\
\hline $\mathrm{HCB}$ & $5.10^{-5}$ & $\mathrm{MRL}^{\mathrm{c}}$ for chronic oral exposure to HCB (ATSDR, 2002b) \\
\hline \multirow{2}{*}{ PBDEs } & 3. $10^{-3}$ & $\mathrm{RfD}^{\mathrm{b}}$ for octabromodiphenylether (ATSDR, 2004 ) \\
\hline & 1. $10^{-2}$ & $\mathrm{RfD}^{\mathrm{b}}$ for decabromodiphenylether (ATSDR, 2004 ) \\
\hline DEHP & 6. $10^{-2}$ & $\mathrm{MRL}^{\mathrm{c}}$ for chronic oral exposure to DEHP (ATSDR, 2002a) \\
\hline \multicolumn{3}{|c|}{$\begin{array}{l}{ }^{\mathrm{a}} \mathrm{MRD} \text { stands for Minimal Risk Dose and is the estimate of the amount of a substance, expressed in mg (kg body } \\
\text { weight.day) }{ }^{-1} \text {, which can be ingested daily over a lifetime by humans without adverse non cancer health effects } \\
\text { b RFD stands for Reference Dose and is an MRD derived by the US Environmental Protection Agency } \\
{ }^{\mathrm{c}} \text { MRL stands for Minimal Risk Level and is an MRD derived by the American Agency for Toxic Substances and } \\
\text { Disease Registry } \\
\text { d TDI stands for tolerable Daily intake and is an MRD derived by the World Health Organisation } \\
\text { e ADI stands for acceptable Daily intake and is an MRD derived by the World Health Organisation }\end{array}$} \\
\hline
\end{tabular}


Table 4: Potency factors used for the calculation of weighed POP masses

\begin{tabular}{|c|c|c|}
\hline & $\begin{array}{l}\text { Potency Factor }{ }^{\mathrm{a}} \\
\text { (kg bw.day) } \mathrm{mg}^{-1}\end{array}$ & Comments \\
\hline $\begin{array}{l}\mathrm{PCDD} / \mathrm{Fs} \\
\text { Dioxin-like PCBs } \\
\mathrm{PBDD} / \mathrm{Fs}\end{array}$ & $1.5610^{5} \mathrm{TEQ}$ & $\begin{array}{l}\text { Potency factor for exposure to dioxin-like compounds with } \\
\text { TEF-values (EPA) (ATSDR, 1998) } \\
\text { Sufficient data supports the concept of using corresponding } \\
\text { TEF values for brominated and chlorinated analogues } \\
\text { (WHO, 1998c) }\end{array}$ \\
\hline PCBs & 2.0 & $\begin{array}{l}\text { Potency factor for oral exposure to commercial PCB } \\
\text { mixtures (EPA) (ATSDR, 2000) }\end{array}$ \\
\hline \multirow{2}{*}{ Chlorinated pesticides } & $3.410^{-1}$ & $\begin{array}{l}\text { Potency factor for DDT (EPA), the lowest potency factor of } \\
\text { all of the considered chlorinated pesticides for which } \\
\text { potency factors were derived (ATSDR, 2002c) }\end{array}$ \\
\hline & 17 & $\begin{array}{l}\text { Potency factor for aldrin (EPA), the highest potency factor } \\
\text { of all of the considered chlorinated pesticides for which } \\
\text { potency factors were derived (ATSDR, 2003) }\end{array}$ \\
\hline PAHs & $4.5-11.7$ & $\begin{array}{l}\text { Lowest and highest reported potency factor for } \\
\text { benzo(a)pyrene (WHO, 1998b) }\end{array}$ \\
\hline $\mathrm{HCB}$ & 1.6 & Potency factor for HCB (EPA) (ATSDR, 2002c) \\
\hline DEHP & $1.410^{-2}$ & Potency factor for DEHP (EPA) (ATSDR, 2002a) \\
\hline
\end{tabular}




\section{Table 5: Maximum and minimum weighed input/output ratios}

\begin{tabular}{lllllll}
\hline & $\begin{array}{l}\text { Input/output } \\
\text { Only flue gas }\end{array}$ & MRDs & $\begin{array}{l}\text { Potency } \\
\text { factors }\end{array}$ & $\begin{array}{l}\text { Input/output } \\
\text { All output } \\
\text { fractions }\end{array}$ & MRDs & $\begin{array}{l}\text { POPs weighed with } \\
\text { factors }\end{array}$ \\
\hline Scenario 1 & Maximum & $7,600,000$ & 470,000 & Maximum & 49,800 & 16,900 \\
& Minimum & $7,200,000$ & 118,000 & Minimum & 3,200 & 890 \\
Scenario 2 & Maximum & 580 & 55 & Maximum & 3.2 & 2.0 \\
& Minimum & 90 & 6 & Minimum & 0.3 & 0.1 \\
Scenario 3 & Maximum & 4,100 & 290 & Maximum & 23 & 11 \\
& Minimum & 600 & 50 & Minimum & 2.0 & 1.0 \\
\hline a in flue gas for & &
\end{tabular}

${ }^{a}$ in flue gas for scenario 1 , in flue gas and granulate fraction of bottom ashes for scenario 2 and 3 